\title{
Low back pain in junior Australian Rules football: a cross-sectional survey of elite juniors, non-elite juniors and non-football playing controls
}

\author{
Wayne Hoskins ${ }^{1 *}$, Henry Pollard ${ }^{1}$, Chris Daff', Andrew Odell ${ }^{3}$, Peter Garbutt ${ }^{4}$, Andrew McHardy ${ }^{1}$, Kate Hardy ${ }^{1}$, \\ George Dragasevic ${ }^{1}$
}

\begin{abstract}
Background: Low back pain in junior Australian Rules footballers has not been investigated despite findings that back pain is more prevalent, severe and frequent in senior footballers than non-athletic controls and findings that adolescent back pain is a strong predictor for adult back pain. The aim of this study was to determine the prevalence, intensity, quality and frequency of low back pain in junior Australian Rules footballers and a control group and to compare this data between groups.
\end{abstract}

Methods: A cross-sectional survey of male non-elite junior $(n=60)$ and elite junior players $(n=102)$ was conducted along with a convenience sample of non-footballers (school children) ( $n=100$ ). Subjects completed a self-reported questionnaire on low back pain incorporating the Quadruple Visual Analogue Scale and McGill Pain Questionnaire (short form), along with additional questions adapted from an Australian epidemiological study. Linear Mixed Model (Residual Maximum Likelihood) methods were used to compare differences between groups. Log-linear models were used in the analysis of contingency tables.

Results: For current, average and best low back pain levels, elite junior players had higher pain levels $(p<0.001)$, with no difference noted between non-elite juniors and controls for average and best low back pain. For low back pain at worst, there were significant differences in the mean pain scores. The difference between elite juniors and non-elite juniors ( $p=0.040$ ) and between elite juniors and controls $(p<0.001)$ was significant, but not between non-elite juniors and controls. The chance of suffering low back pain increases from $45 \%$ for controls, through 55\% for non-elite juniors to $66.7 \%$ for elite juniors. The chance that a pain sufferer experiences chronic pain is $16 \%$ for controls and $41 \%$ for non-elite junior and elite junior players. Elite junior players experienced low back pain more frequently ( $p=0.002$ ), with no difference in frequency noted between non-elite juniors and controls. Over $25 \%$ of elite junior and non-elite junior players reported that back pain impacted their performance some of the time or greater.

Conclusions: This study demonstrated that when compared with non-elite junior players and non-footballers of a similar age, elite junior players experience back pain more severely and frequently and have higher prevalence and chronicity rates.

\section{Background}

There has been increased awareness of low back pain (LBP) in children and adolescents with several studies showing that LBP is highly prevalent in the early years of

\footnotetext{
* Correspondence: waynehoskins@iinet.net.au

'Department of Chiropractic, Macquarie University, Sydney, NSW 2109, Australia

Full list of author information is available at the end of the article
}

life $[1,2]$. LBP increases with age during the first decades [3], with prevalence increasing significantly following sexual maturity [4]. It has been theorized that LBP in childhood may have important consequences for chronic LBP in adulthood [5]. This theory has been validated with clear correlations between LBP in childhood and adolescence and LBP in adulthood [6]. Hestbaek et al. in a large longitudinal study found LBP in adolescence to be a
Ciomed Central 
significant risk factor for LBP in adulthood with odds ratios as high as four [6]. A dose-response association was also demonstrated: the more days with LBP, the higher the risk of future LBP. These findings are supported by research which demonstrates that $90 \%$ of schoolchildren with LBP suffer from LBP 25 years later [7].

Questions have been raised regarding LBP at the junior level of sporting competition given that participation in adolescent sports has been found to be a risk factor for LBP [8] and sport participation produces higher LBP prevalence than in non-athletes [9], particularly in males [1]. It is believed that adolescent athletes with less musculoskeletal maturity may be at a heightened risk for more severe and permanent skeletal damage and structural abnormalities, particularly when exposed to years of intense athletic training [10].

There are no specific studies investigating LBP in junior Australian Rules footballers. This is despite the popularity of the sport and recent evidence showing that elite senior and semi-elite footballers experience LBP more severely and frequently than non-athletic controls, with this trend being more evident in elite players [11]. Thus, the primary objective of the present study was to determine the prevalence, intensity, quality and frequency of LBP in junior Australian Rules footballers. The secondary objective was to compare this data between non-elite junior and elite junior participants and with that of a control group of non-footballers.

\section{Methods}

The study was designed as a cross-sectional survey of male junior Australian Rules football participants. Players were drawn from local underage competitions (classified as non-elite junior), the Victorian state based under 18 TAC Cup (classified as elite junior) and a convenience sample of high school students (classified as controls). The study was approved by the Macquarie University Human Ethics Committee.

The Victorian Football League (VFL) was approached by the authors to participate in the study. They agreed and randomly selected 3 TAC Cup teams to provide players for the elite junior group. Non-elite junior players were selected from a convenience sample of junior football clubs from different states. For clubs to consent to participate it was required that they provide access to their entire player rosters to ensure $100 \%$ compliance which would assist in providing an accurate reflection of the status of LBP in the participating clubs. The survey was completed during the 2006 season. All players on the playing lists of the selected clubs were invited to participate and complete the survey with responses remaining confidential. Controls were drawn from a convenience sample of male school students, with the specification that they not participate in Australian Rules football.

The study was presented to the clubs and players as a LBP survey. Questionnaires were either administered by an author of the study or by an official representing the participating club, at the preference of the club. In the case of the club wishing to administer the survey, the questionnaires were mailed out along with consent forms and instructions describing the purposes and procedures of the study and how the instruments were to be administered. This was followed by a telephone call to confirm that all procedures would be correctly administered, to ensure players completed every question and to make certain the club officials were qualified to answer questions of the players. None of the assessors were involved in the analysis of the data. Analysis was provided by a person independent to each of the group allocations.

The questionnaire was developed using the validated and reliable Quadruple Visual Analogue Scale (QVAS) [12], the McGill Pain Questionnaire (short-form) (MPQSF) [13], along with a series of questions either adapted from an Australian LBP epidemiological study with permission of the author [14] or that the authors developed themselves and thoroughly pilot tested.

The additional questions were:

- How old were you when you had your first ever attack or episode of LBP?

- If applicable, was this a result of your sporting commitments and activities or not related to this?

- When did your current episode of LBP commence?

- If applicable, was this a result of your sporting commitments and activities or not related to this?

- How often do you experience LBP?

- Do you feel that your low back pain negatively effects or impacts your performance?

To assist with answering the questions a diagram of a mannequin that defined the anatomical boundaries of the low back as a shaded area between the last ribs and the gluteal folds was provided. For the purposes of this survey the shaded area represented the low back and subjects were told to focus only on LBP and not other sources of pain. This area was found to be the most commonly used in a review of methodologically sound LBP prevalence studies [15].

The forms were manually entered using Microsoft Excel $^{\circ}$ and analyzed using GenStat. Descriptive statistics are used to report player characteristics. Linear Mixed Model (Residual Maximum Likelihood) methods were used to compare differences between groups because of imbalance in replication. Log-linear models were used in the analysis of contingency tables. For all tests a $\mathrm{p}$ value 
$<0.05$ was considered significant, however actual $\mathrm{p}$ values are reported in the study.

\section{Results}

Three of the 12 TAC Cup teams, 3 non-elite junior clubs and 2 high schools participated. The subject characteristics of the different groups are shown in table 1 . The results of the QVAS questionnaire are presented in table 2. For LBP now, pain levels were significantly different between groups ( $\mathrm{p}<0.001)$. For the LBP average and LBP at best, there were significant differences across the three groups ( $p<0.001)$, with no difference between non-elite junior players and controls, but strong differences between them and elite players. For LBP at worst, there were significant differences in the mean pain scores across the three groups $(\mathrm{p}<0.001)$. The difference between elite juniors and non-elite juniors $(\mathrm{p}=0.040)$ and between elite juniors and controls $(\mathrm{p}<0.001)$ was significant, but not between non-elite juniors and controls.

The results of the overall pain question are presented in table 2. There were few players with distressing or horrible LBP and the percentage of elite juniors having no pain appeared low.

The results of the MPQ-SF are presented in table 3. Analysing the MPQ-SF, there were no significant differences in the mean sensory values across the three groups ( $\mathrm{p}=0.068$ ). The difference between elite juniors and non-elite juniors just failed to be significant ( $\mathrm{p}=$ 0.057). This difference may have been significant had the study had larger subject numbers. There were no significant differences in the mean affective values $(\mathrm{p}=$ $0.575)$ and MPQ-SF total questions $(\mathrm{p}=0.112)$ across the three groups.

There were a substantial number of players who could not recall when they first experienced LBP $(36.3 \%, \mathrm{n}=$ 37 of elite juniors, $51.7 \%, \mathrm{n}=31$ of non-elite juniors and $41.0 \%, \mathrm{n}=41$ of controls). The mean (SE) age of first onset LBP were: elite juniors 15.18 (0.20), non-elite juniors $13.68(0.31)$, and controls $13.88(0.24)$. Of the elite juniors, $8.8 \%, \mathrm{n}=9$ said that they had not experienced back pain, $6.7 \%, \mathrm{n}=4$ of non-elite juniors and $18.0 \%, \mathrm{n}=18$ of controls. Using the players who could recall first onset of LBP as being representative of the population, the mean ages of first onset LBP was different across groups $(p<0.001)$, but there was no difference between non-elite junior players and controls $(\mathrm{p}=$ 0.612). The age of first onset LBP for elite juniors was significantly older, by 1.3 years $(\mathrm{p}<0.001)$. When asked whether their first onset LBP was caused by sport or not $71.0 \%, \mathrm{n}=66$ of elite juniors, $66.1 \%, \mathrm{n}=37$ of nonelite juniors and $69.5 \%, \mathrm{n}=57$ of controls indicated that their first onset of LBP was due to sport, although this was non-significant $\left(\mathrm{X}^{2}=0.39, \mathrm{df}=2, \mathrm{p}=0.821\right)$.

With regards to the commencement of the current episode of LBP the probability of a player suffering LBP varied significantly across groups $\left(\mathrm{X}^{2}=9.71, \mathrm{df}=2, \mathrm{p}=\right.$ 0.008 ). The chance of suffering LBP increases from $45 \%$ for controls), through $55 \%$ for non-elite juniors to $66.7 \%$ for elite juniors. Defining acute LBP as pain commencing within the last three months, and chronic LBP as pain commencing beyond the last three months then for players who suffer LBP, the probability of LBP being acute is significantly different across groups $\left(X^{2}=9.64\right.$, $\mathrm{df}=2, \mathrm{p}=0.008)$. The chance that a pain sufferer experiences chronic pain is $16 \%$ for controls, and $41 \%$ for non-elite juniors and elite juniors. When asked if their current episode of LBP was due to sporting commitments or activities the percentages across groups was not significant $\left(\mathrm{X}^{2}=5.36, \mathrm{df}=2, \mathrm{p}=0.069\right)$. There was no difference in probability that sport was the cause of the current LBP for non-elite juniors and controls $\left(\mathrm{X}^{2}=\right.$ $0.261, \mathrm{df}=1, \mathrm{p}=0.609$ ) but was significantly more likely for elite juniors $\left(\mathrm{X}^{2}=5.094, \mathrm{df}=1, \mathrm{p}=0.024\right)$.

The frequency of LBP is presented in table 2 . The distribution of episodes was different across groups $\left(X^{2}=27.27\right.$, $\mathrm{df}=14, \mathrm{p}=0.018)$. The difference between non-elite

Table 1 Descriptive statistics and distribution for the ages of subjects in the study

\begin{tabular}{|c|c|c|c|c|c|c|}
\hline & Elite junior & & Non-elite juni & & Control & \\
\hline Number & 102 & & 60 & & 100 & \\
\hline Mean (SD) & $17.2(0.576)$ & & $15.8(0.676)$ & & $15.8(1.237)$ & \\
\hline Median & 17 & & 16 & & 16 & \\
\hline \multirow[t]{2}{*}{ Range } & $16-18$ & & $14-17$ & & $14-18$ & \\
\hline & Frequency & & & Percentage & & \\
\hline Age & Elite junior & Non-elite junior & Control & Elite junior & Non-elite junior & Control \\
\hline 14 & 0 & 1 & 24 & 0 & 1.7 & 24.0 \\
\hline 15 & 0 & 17 & 12 & 0 & 28.3 & 12.0 \\
\hline 16 & 10 & 34 & 26 & 9.8 & 56.7 & 26.0 \\
\hline 17 & 66 & 8 & 35 & 64.7 & 13.3 & 35.0 \\
\hline 18 & 26 & 0 & 3 & 25.5 & 0 & 3.0 \\
\hline
\end{tabular}


Table 2 Analysis of the Quadruple Visual Analogue Scale (QVAS) questionnaire and results of the overall pain question from the MPQ-SF and frequency of LBP episodes

\begin{tabular}{|c|c|c|c|c|c|c|}
\hline QVAS & $\begin{array}{l}\text { Elite junior } \\
(n=102)\end{array}$ & & $\begin{array}{l}\text { Non-elite jur } \\
(n=60)\end{array}$ & & $\begin{array}{l}\text { Control } \\
(n=100)\end{array}$ & \\
\hline LBP now mean (SE) & $21.32(2.24)$ & & $11.87(2.02)$ & & $6.57(1.18)$ & \\
\hline LBP average mean (SE) & $21.68(1.92)$ & & $11.90(1.60)$ & & $11.21(1.28)$ & \\
\hline LBP best mean (SE) & $6.50(1.13)$ & & $2.97(0.94)$ & & $1.67(0.36)$ & \\
\hline \multirow[t]{2}{*}{ LBP worst mean (SE) } & $48.63(2.83)$ & & $39.03(3.69)$ & & $31.71(2.86)$ & \\
\hline & Frequency & & & Percentage & & \\
\hline Overall pain & $\begin{array}{l}\text { Elite junior } \\
(n=102)\end{array}$ & $\begin{array}{l}\text { Non-elite junior } \\
(n=60)\end{array}$ & $\begin{array}{l}\text { Control } \\
(n=100)\end{array}$ & $\begin{array}{l}\text { Elite junior } \\
(n=102)\end{array}$ & $\begin{array}{l}\text { Non-elite junior } \\
(n=60)\end{array}$ & $\begin{array}{l}\text { Control } \\
(n=100)\end{array}$ \\
\hline No pain & 29 & 24 & 41 & 28.4 & 40.0 & 41.0 \\
\hline$\overline{\text { Mild }}$ & 43 & 23 & 40 & 42.2 & 38.3 & 40.0 \\
\hline Discomforting & 24 & 12 & 15 & 23.5 & 20.0 & 15.0 \\
\hline Distressing & 5 & 1 & 4 & 4.9 & 1.7 & 4.0 \\
\hline Horrible & 1 & 0 & 0 & 1.0 & 0 & 0 \\
\hline Frequency of pain & $\begin{array}{l}\text { Elite junior } \\
(n=102)\end{array}$ & $\begin{array}{l}\text { Non-elite junior } \\
(n=60)\end{array}$ & $\begin{array}{l}\text { Control } \\
(n=100)\end{array}$ & $\begin{array}{l}\text { Elite junior } \\
(n=102)\end{array}$ & $\begin{array}{l}\text { Non-elite junior } \\
(n=60)\end{array}$ & $\begin{array}{l}\text { Control } \\
(n=100)\end{array}$ \\
\hline No pain & 8 & 6 & 6 & 7.8 & 10.0 & 6.0 \\
\hline Daily & 30 & 7 & 12 & 29.4 & 11.7 & 12.0 \\
\hline Weekly & 9 & 7 & 9 & 8.8 & 11.7 & 9.0 \\
\hline Fortnightly & 12 & 8 & 7 & 11.8 & 13.3 & 7.0 \\
\hline Monthly & 11 & 4 & 9 & 10.8 & 6.7 & 9.0 \\
\hline 3 Monthly & 1 & 4 & 8 & 1.0 & 6.7 & 8.0 \\
\hline 6 monthly & 5 & 5 & 15 & 4.9 & 8.3 & 15.0 \\
\hline Yearly & 26 & 19 & 34 & 25.5 & 31.7 & 34.0 \\
\hline
\end{tabular}

juniors and controls was not significant $\left(\mathrm{X}^{2}=4.41, \mathrm{df}=7\right.$, $\mathrm{p}=0.732)$, while elite juniors were strongly significantly different by comparison $\left(\mathrm{X}^{2}=22.86, \mathrm{df}=7, \mathrm{P}=0.002\right)$.

When the elite junior and non-elite junior players were asked whether LBP impacted their performance there was no statistical significance in distributions $\left(\mathrm{X}^{2}=3.24, \mathrm{df}=3, \mathrm{p}=0.356\right)$. For the elite juniors $33.3 \%, \mathrm{n}=34$ said LBP did not impact their performance, $40.2 \%, n=42$ said it did little of the time and $21.6 \%, n=22$ some of the time. For the non-elite junior players $43.3 \%, n=26$ said LBP did not impact their performance, $26.7 \%, \mathrm{n}=16$ said it did little of the time and $25.0 \%, \mathrm{n}=15$ some of the time.

\section{Discussion}

This study demonstrated that when compared with non-elite junior players and non-football playing school children of a similar age, elite junior Australian Rules football players experience LBP more severely and frequently and have higher prevalence and chronicity rates. Although affected by recall bias and low response rate, the elite junior players experience first time onset LBP at an older age at an age typical of entry into underage elite training programs. The elite juniors did not attribute first time LBP to be due to sporting commitments or activities more so than non-elite junior players or school children. However, sporting commitments or activities were attributed to cause a high percentage of first time LBP in all groups. Elite juniors did attribute sporting commitments or activities to be more likely to cause their current LBP episode. Although there was no difference between the elite junior and non-elite junior players in their belief of whether LBP impacted their performance, both groups had over $25 \%$ report that LBP affected their performance some of the time or greater. Of interest, the elite juniors have a prevalence

Table 3 Analysis of the McGill Pain Questionnaire (short form) (MPQ-SF)

\begin{tabular}{lllll}
\hline MPQ-SF & $\begin{array}{l}\text { Elite junior } \\
(\mathbf{n}=\mathbf{1 0 2})\end{array}$ & $\begin{array}{l}\text { Non-elite junior } \\
(\mathbf{n}=\mathbf{6 0})\end{array}$ & $\begin{array}{l}\text { Control } \\
(\mathbf{n}=\mathbf{1 0 0})\end{array}$ & P value between groups \\
\hline Sensory questions (SE) & $14.97(1.28)$ & $10.95(1.67)$ & $11.28(1.29)$ & 0.068 \\
\hline Affective questions (SE) & $8.66(1.38)$ & $6.81(1.31)$ & $7.05(1.23)$ & 0.575 \\
\hline Total questions (SE) & $13.29(1.21)$ & $9.84(1.58)$ & $10.16(1.22)$ & 0.112 \\
\hline
\end{tabular}


and overall LBP rating the same as semi-elite senior Australian football code participants, using the same research methodology [11].

Strengths of our study include the use of validated questionnaires to quantify the intensity (QVAS) and quality of LBP (MPQ-SF). Functional disability associated with LBP was not determined. This important aspect was not investigated as it was felt that validated questionnaires in use to determine these parameters are not created for elite athletic populations. As far as we are aware, this is the first study to investigate LBP in junior Australian Rules footballers.

Limitations exist in the study conducted. Firstly, the convenience sample taken for the non-football playing school children and non-elite junior players is not a random population sample and may not be representative. However, random sampling not producing a $100 \%$ response rate has been discussed as potentially leading to overestimates of LBP in similar research $[11,16]$. Our controls were used because of their likely non-elite junior sporting participation and likelihood to be matched for age. It should be noted that at school age most children participate in some form of recreational or organised sport either at school or externally. That is why they were termed non-footballers, with the important finding of our study being that their LBP profile largely does not differ from junior footballers. Future study would benefit from documenting what sporting participation, if any, is performed by the control group. Secondly, there was a difference in numbers between the groups, with a larger number of non-elite junior players being preferred. Future study would also benefit from larger total numbers. Thirdly, although ages were close, it was difficult to achieve a complete match between groups, largely due to junior football clubs often finishing before the under 18 level and school children finishing their eduction at an earlier mean age than the elite juniors. Fourthly, as some questions asked were retrospective in nature, there is likely an element of recall bias in the answers to some questions. This is in particular for questions regarding first time onset of LBP, with questions regarding the current episode of LBP being less affected. Lastly, there may be issues with reliability with adolescents competing the questionnaires, although this would have been affected equally between groups.

The older age of onset in LBP of elite juniors is interesting given the increased prevalence, severity, frequency and chronicity in their LBP. A large cross sectional survey has found that adolescents are at a greater risk of LBP if they have low isometric muscle endurance in the back extensors, with no associations found for aerobic fitness, functional strength, flexibility, or physical activity level after adjustment for muscle endurance [17]. It may be that elite juniors are initially protected from LBP due to their increased physical fitness, but this is lost following the excessive spinal loading [9] and high training duration [18] these players face when they enter the elite junior pathway. To support this, sporting participation in the general population is known to result in less frequent LBP, although once LBP is established, sporting participation contributes to increased severity of pain [19]. Elite juniors also face pressure to play and train with LBP (and other injuries) given injuries can affect future selection to professional senior clubs in the Australian Football League (AFL). However, future research would benefit from the inclusion of training and competition volume to more clearly identify its role in the increased incidence of LBP occurring in elite junior footballers. Other potential reasons for the increased incidence of LBP in elite adolescent Australian Rules footballers includes the likely increased prevalence of weight lifting training and the effects that increased loading and training volume may have on the developing skeleton [10].

It has previously been documented that LBP is rarely a self-limiting disorder but characterized by unpredictable variations in pain status, with temporary, rather than permanent remissions [20]. Although these studies are based on adult populations, given that the natural history of LBP in adolescence involves a significantly increased risk of adult LBP, it has been suggested that it might be counterproductive to postpone treatment/prevention until the problems become more severe and chronic [6]. This would require a greater understanding of the knowledge of risk factors for LBP in elite junior Australian Rules footballers along with research investigating prevention and treatment interventions. Hestbaek et al. have suggested a change in focus from the adult to the young population in relation to research, prevention, and treatment of LBP [6]. However, it remains to be seen whether a greater focus on prevention and treatment can eliminate the risk and consequences of future LBP episodes and minimise future chronicity. Future study should assess the potential that LBP has for later career and end of career injury occurring in elite junior players.

Although most LBP is non-specific in nature [1], adolescent athletes presenting with LBP may have a pathologic cause for their symptoms [21]. For this reason, it is important for those caring for younger athletes to maintain a high index of suspicion for some of the more common pathologic causes of LBP in this population. Sports-related diagnoses that must be considered include disc-related back pain, atypical Scheuermann's kyphosis, spondylolysis, and spondylolisthesis [22]. It is unclear whether football code players have a greater prevalence of radiographic lumbar spine abnormalities, including spondylolysis and spondylolisthesis, as age-matched 
controls [23]. This casts doubts on the usefulness of routine radiographic screening. Other research has documented that junior athletes with chronic LBP form a population of adolescents who have degenerative disc disease (DDD) identified on MRI [24]. For adolescent athletes with DDD, the relative risk of reporting recurrent LBP up to the age of 23 years is 16 compared with those having no disc degeneration [25]. Furthermore, disc protrusion and Scheuermann-type changes also contribute to the risk of persistently recurrent LBP at a later age [25]. LBP in adolescent athletes is a problem that should not be ignored but instead fully evaluated.

Future study should target elite junior footballers to determine whether LBP renders them more susceptible to developing other injuries given LBP in senior footballers produces a $29 \%$ increased risk of other injury [26]. Already evidence exists documenting that LBP produces changes in the neuromuscular control of the lumbopelvis [27] and in athletes it produces altered muscle response patterns required for lumbopelvic stabilization during sudden trunk loading following clinical recovery from LBP [28]. These changes in lumbopelvic stabilisation and neuromuscular control could explain the high rates of injuries such as hamstring injuries and groin injuries, which occur in elite junior players [29]. If LBP is determined to be a risk factor for injuries, it should be assessed whether prevention or effective treatment reduces this risk.

Considering that a high percentage of elite junior players stated that LBP impacted their performance some of the time or greater, this should be further investigated. Evidence exists that college level athletes with a history of low back injury with resolved LBP demonstrate significantly diminished athletic performance in a $20 \mathrm{~m}$ shuttle run test compared with a healthy group [30]. This is of immense consideration for the elite juniors who get tested for sprint speed and endurance (through a beep test) at the AFL draft camp, results which can affect future career prospects.

\section{Conclusions}

This study demonstrated that elite junior Australian Rules footballers strongly experience LBP more severely, frequently and with higher prevalence and chronicity than non-elite junior Australian Rules footballers and non-football playing school children, who share a similar pain profile. This suggests that Australian Rules football participation is not a risk for adolescent LBP, but elite junior participation is. Future research is required to investigate the consequences of these findings, to determine whether LBP produces a greater risk of other injuries, leads to later or post-career LBP or impacts player performance. In addition, risk factors for elite junior
LBP need to be identified along with best practices for prevention and treatment.

\section{Acknowledgements}

No source of funding was used in the preparation of this manuscript. The authors would like to acknowledge Mick O'Neil for the statistical analysis and the following people who contributed to the study: David Code (Victorian Football League), Lilian Hoskins (Ramsgate RSL), Rob Young (Research), Michael Hoskins (Sorrento-Duncraig), Ron Webb and Karen Davies (Broughton Anglican College) and Alan McManus and John Tannous (Magdalene Catholic College).

\section{Author details}

'Department of Chiropractic, Macquarie University, Sydney, NSW 2109, Australia. ${ }^{2}$ Harbord Village Chiropractic, Freshwater, NSW 2096, Australia ${ }^{3}$ Norwest Orthopaedic and Sports Physiotherapy, Norwest, NSW 2153, Australia. ${ }^{4}$ Enhance Chiropractic and Massage Sports Injury Centre, Ngunnawal, ACT 2913, Australia.

\section{Authors' contributions}

WH conceived the idea of the study. All authors were involved in recruitment of subjects and data entry. WH and HP contributed to writing an initial draft document. All authors contributed to the re-writing of this paper. All of the authors participated in the editing and revisions of the multiple drafts that existed between the initial and final draft. All authors read and approved the final manuscript.

\section{Competing interests}

The authors declare that they have no competing interests.

Received: 11 November 2009 Accepted: 19 October 2010 Published: 19 October 2010

\section{References}

1. Burton AK, Clarke RD, McClune TD, Tillotson KM: The natural history of low back pain in adolescents. Spine 1996, 21(20):2323-8.

2. Balagué F, Dudler J, Nordin M: Low-back pain in children. Lancet 2003, 361:1403-4.

3. Salminen JJ, Erkintalo M, Laine M, Pentti J: Low back pain in the young. $A$ prospective three-year follow-up study of subjects with and without low back pain. Spine 1995, 20(19):2101-7.

4. LeResche L, Mancl LA, Drangsholt MT, Saunders K, Korff MV: Relationship of pain and symptoms to pubertal development in adolescents. Pain 2005, 118(1-2):201-9.

5. Watson KD, Papageorgiou AC, Jones GT, Taylor S, Symmons DP, Silman AJ, Macfarlane GJ: Low back pain in schoolchildren: occurrence and characteristics. Pain 2002, 97:87-92.

6. Hestbaek L, Leboeuf-Yde C, Kyvik KO, Manniche C: The course of low back pain from adolescence to adulthood: eight-year follow-up of 9600 twins. Spine 2006, 31(4):468-72.

7. Harreby M, Kjer J, Hesselsøe G, Neergaard K: Epidemiological aspects and risk factors for low back pain in 38-year-old men and women: a 25-year prospective cohort-study of 640 Danish school children. Eur Spine J 1996, 5(5):312-8.

8. Kujala UM, Taimela S, Oksanen A, Salminen JJ: Lumbar mobility and low back pain during adolescence. A longitudinal three-year follow-up study in athletes and controls. Am J Sports Med 1997, 25(3):363-8.

9. Kujala UM, Taimela S, Erkintalo M, Salminen KK, Kaprio JJ: Low-back pain in adolescent athletes. Med Sci Sports Exerc 1996, 28(2):165-70.

10. Wojtys EM, Ashton-Miller JA, Huston LJ, Moga PJ: The association between athletic training time and the sagittal curvature of the immature spine. Am J Sports Med 2000, 28(4):490-8.

11. Hoskins W, Pollard H, Daff C, Odell A, Garbutt P, McHardy A, Hardy K, Dragasevic G: Low back pain status in elite and semi-elite Australian football codes: a cross-sectional survey of football (soccer), Australian rules, rugby league, rugby union and non-athletic controls. $B M C$ Musculoskelet Disord 2009, 10:38. 
12. Jensen MP, Karoly P: Self report scales and procedures for assessing pain in adults. In Handbook of pain assessment. Edited by: Turk DC, Melzack R. New York, Guildford Press; 1993:15-34

13. Grafton KV, Foster NE, Wright CC: Test-retest reliability of the Short-Form McGill Pain Questionnaire: assessment of intraclass correlation coefficients and limits of agreement in patients with osteoarthritis. Clin J Pain 2005, 21:73-82.

14. Walker BF, Muller R, Grant WD: Low back pain in Australian adults: prevalence and associated disability. J Manipulative Physiol Ther 2004, 27:238-44

15. Walker BF: The prevalence of low back pain: a systematic review of the literature from 1966 to 1998. J Spinal Disord 2000, 13:205-17.

16. Bahr R, Andersen SO, Loken S, Fossan B, Hansen T, Holme I: Low back pain among endurance athletes with and without specific back loading-a cross-sectional survey of cross-country skiers, rowers, orienteerers, and nonathletic controls. Spine 2004, 29:449-54.

17. Bo Andersen L, Wedderkopp N, Leboeuf-Yde C: Association between back pain and physical fitness in adolescents. Spine 2006, 31(15):1740-4.

18. Kujala UM, Salminen JJ, Taimela S, Oksanen A, Jaakkola L: Subject characteristics and low back pain in young athletes and nonathletes. Med Sci Sports Exerc 1992, 24(6):627-32.

19. Jacob T, Baras M, Zeev A, Epstein L: Physical activities and low back pain: a community-based study. Med Sci Sports Exerc 2004, 36:9-15.

20. Hestbaek L, Leboeuf-Yde C, Engberg M, Lauritzen T, Bruun NH, Manniche C: The course of low back pain in a general population. Results from a 5year prospective study. J Manipulative Physiol Ther 2003, 26:213-9.

21. Micheli $\sqcup$, Wood R: Back pain in young athletes. Significant differences from adults in causes and patterns. Arch Pediatr Adolesc Med 1995, 149(1):15-8.

22. Waicus KM, Smith BW: Back injuries in the pediatric athlete. Curr Sports Med Rep 2002, 1(1):52-8.

23. Jones DM, Tearse DS, el-Khoury GY, Kathol MH, Brandser EA: Radiographic abnormalities of the lumbar spine in college football players. A comparative analysis. Am J Sports Med 1999, 27(3):335-8.

24. Dimar JR, Glassman SD, Carreon LY: Juvenile degenerative disc disease: a report of 76 cases identified by magnetic resonance imaging. Spine J 2007, 7(3):332-7.

25. Salminen JJ, Erkintalo MO, Pentti J, Oksanen A, Kormano MJ: Recurrent low back pain and early disc degeneration in the young. Spine 1999, 24(13):1316-21.

26. McManus A, Stevenson M, Finch CF, Elliot B, Hamer P, Lower A, Bulsara M: Incidence and risk factors for injury in non-elite Australian Football. J Sci Med Sport 2004, 7(3):384-91.

27. Demoulin C, Distrée V, Tomasella M, Crielaard JM, Vanderthommen M: Lumbar functional instability: a critical appraisal of the literature. Ann Readapt Med Phys 2007, 50(8):677-84.

28. Cholewicki J, Greene HS, Polzhofer GK, Galloway MT, Shah RA, Radebold A: Neuromuscular function in athletes following recovery from a recent acute low back injury. J Orthop Sports Phys Ther 2002, 32(11):568-75.

29. Orchard J, Wood T, Seward H, Broad A: Comparison of injuries in elite senior and junior Australian football. J Sci Med Sport 1998, 1(2):83-8.

30. Nadler SF, Moley P, Malanga GA, Rubbani M, Prybicien M, Feinberg JH: Functional deficits in athletes with a history of low back pain: a pilot study. Arch Phys Med Rehabil 2002, 83:1753-8.

\section{Pre-publication history}

The pre-publication history for this paper can be accessed here: http://www.biomedcentral.com/1471-2474/11/241/prepub

doi:10.1186/1471-2474-11-241

Cite this article as: Hoskins et al: Low back pain in junior Australian Rules football: a cross-sectional survey of elite juniors, non-elite juniors and non-football playing controls. BMC Musculoskeletal Disorders 2010 $11: 241$ 